- Research Paper

\title{
A Tractable Solution for Engineering Calculations on Buoyancy Dominated Turbulent Non-Premixed Flames
}

\author{
H. Q. Dong ${ }^{1}$, J. P. Garo ${ }^{1}$, B. Magnognou ${ }^{1}$ and H. Y. Wang ${ }^{1}$ \\ ${ }^{1}$ Institut P', Fluides-Thermique-Combustion, CNRS, ENSMA, Université de Poitiers, France
}

\begin{abstract}
The modelling of molecular species and smoke concentrations in turbulent buoyant intermediate free pool and enclosure fires is described. The numerical model solves the time-dependent reactive flow, Navier-Stokes equations, coupled with submodels for soot formation and thermal radiation transfer. A comparison is performed, and differences are discussed between the values of the temperature, velocity, carbon monoxide and smoke concentrations in the fire from the current study and the literature. The current modeling indicates that CO generation is relatively independent of position in the overfire region, and is correlated solely as a function of mixture fraction. No link between the soot concentration and the mixture fraction is found, which suggests that soot formation in the fires is fundamentally controlled by the transient phenomena. For a free pool-like fire, the computed peak temperature, velocity and CO concentration differ from the experimental values by less than $15 \%$. The soot volume fraction differs significantly from the experimental data only in the fuel-lean, thermal plume region.
\end{abstract}

Keywords: Fire models, Free pool fire, Enclosure fire, Carbon monoxide, Soot concentration

\section{INTRODUCTION}

Complexes structures in many buildings lead to a new risks for human life and building. Moreover, fire resistance of the enclosure elements depends on the local energy balance, which is greatly affected by soot production due to the strong radiation heat transfer from the flames and hot gases to the enclosure surfaces. Intensive research has been carried over decades on the fire dynamics [1-7], though only a small proportion of the work has looked specifically on the toxicity of smoke and gases from the fire [8-11]. Enclosure fire also imply poor entrainment, therefore enhanced carbon monoxide and soot productions which is the yields of incomplete combustion [8, 11]. It also underlies Koylu [9] and Orloff success [10] in correlating concentration of CO in terms of the local average mixture fraction.

Most of the previously developed soot [12] and CO [13] models in non-premixed flames are impractical for use in fire safety engineering due to their complexity, computational cost, or large number of fuel-specific parameters that are not easily 
obtained. In the Fire Dynamics Simulator (FDS) code [14], based on a mixing-controlled combustion model, soot production is derived from the fraction of the fuel mass that is converted into soot, in addition to a radiative loss fraction. All these parameters can be specified for well-ventilated fires for adjusting the species and flame temperature, but not for an enclosure fire. In the work of Chen [15], a stepwise turbulent energy cascade is supposed to take place in combustion from mean flow down to Kolmogorov scale. For this, an extremely small grid size $(\mathrm{mm})$ is required to fully resolve the complex flow instabilities from a turbulent buoyant flame, making practical fire simulations difficult. In the current model, the subgrid scale mixing-controlled combustion via two chemical reaction steps and a global soot formation model are incorporated into FDS. This allows to minimize the computational expense and, an adequate resolution of the fire plume can be achieved with a large spatial resolution which is related to the Heat Release Rate [14]. A comparison from the current study and the literature [10, 11, 13] is performed on the turbulent combustion and soot models through the temperature, velocity, carbon monoxide and smoke concentrations in the fire. This entirely tractable solution gives sufficiently accurate predictions in non-premixed turbulent flames for engineering calculations.

\section{PHYSICAL MODELLING}

This section outlines the physico-mathematical models invoked for the computations. The basis of the analysis is the conservation equations of mass, momentum, energy and species, a set of three-dimensional elliptic, time-dependent Navier-Stokes equations [14]. These equations are the mathematical representation of the reacting flow phenomena of interest here.

\subsection{Subgrid Kinetic Energy}

In Large Eddy Simulation (LES), the Sub-grid scale (SGS) kinetic energy represents the unresolved turbulent energy and needs to be modelled. The subgrid kinetic energy, $\mathrm{k}$, is solved by a transport equation, and its basic form was inspired by the work of Menon [16].

$$
\frac{\partial \rho \mathrm{k}}{\partial \mathrm{t}}+\frac{\partial\left(\rho \mathrm{u}_{\mathrm{i}} \mathrm{k}\right)}{\partial \mathrm{x}_{\mathrm{j}}}=\frac{\partial}{\partial \mathrm{x}_{\mathrm{j}}}\left(\mu_{\mathrm{t}} \frac{\partial \mathrm{k}}{\partial \mathrm{x}_{\mathrm{j}}}\right)-\tau_{\mathrm{ij}, \mathrm{SGS}} \frac{\partial \mathrm{u}_{\mathrm{i}}}{\partial \mathrm{x}_{\mathrm{j}}}-\rho \varepsilon
$$

Here $\mu_{\mathrm{t}}$ is the eddy viscosity from the analysis of Smagorinsky [14]. The terms on the right side of equation represent, respectively, the transport, the production and the dissipation of subgrid kinetic energy. The production terms is determined from the shear stresses, $\tau_{\mathrm{ij}, \mathrm{SGS}}$, which are evaluated from the resolved dynamic field. The dissipation rate, $\varepsilon$, is modelled from the characteristic grid size, $\Delta$, and the SGS kinetic energy, $\mathrm{k}$.

$$
\varepsilon=\mathrm{c}_{\varepsilon} \frac{\mathrm{k}^{3 / 2}}{\Delta} \text { avec } \quad \mathrm{c}_{\varepsilon}=0.7
$$




\subsection{Combustion Via Two Chemical Reaction Steps}

The combustion processes are governed by the convection-diffusion equations for the mass fraction, $\mathrm{Y}_{\mathrm{i}}$, of the six major chemical species, such as $\mathrm{C}_{\mathrm{m}} \mathrm{H}_{\mathrm{n}}, \mathrm{O}_{2}, \mathrm{CO}, \mathrm{CO}_{2}, \mathrm{H}_{2} \mathrm{O}$ and $\mathrm{N}_{2}$. The mixing-controlled combustion via two chemical reaction steps for CO formation, is assumed.

$$
\begin{aligned}
& \mathrm{C}_{\mathrm{m}} \mathrm{H}_{\mathrm{n}}+\left(\frac{\mathrm{m}}{2}+\frac{\mathrm{n}}{4}\right) \mathrm{O}_{2} \rightarrow \mathrm{mCO}+\frac{\mathrm{n}}{2} \mathrm{H}_{2} \mathrm{O} \\
& \mathrm{CO}+\frac{1}{2} \mathrm{O}_{2} \rightarrow \mathrm{CO}_{2}
\end{aligned}
$$

The postulated model deviates from the resolved view of reaction because processes of turbulent energy cascade are not explicitly considered. The combustion rates occurring at resolved scales are therefore controlled by the eddy mixing rate with which the local reaction rates of fuel and CO, are calculated from an EDC [15].

$$
\dot{\omega}_{\mathrm{i}}=\frac{\mathrm{d} \rho \mathrm{Y}_{\mathrm{i}}}{\mathrm{dt}}=-\rho \tau_{\mathrm{mix}} \min \left(\mathrm{Y}_{\mathrm{i}}, \frac{\mathrm{Y}_{\mathrm{O} 2}}{v_{\mathrm{g}, \mathrm{i}}}\right) \cdot \mathrm{H}_{\mathrm{eav}}\left(\mathrm{Y}_{\mathrm{O} 2}-\mathrm{Y}_{\mathrm{O} 2, \mathrm{Lim}}\right)
$$

where $v_{\mathrm{g}, \mathrm{i}}$ denotes the stoichiometric coefficient, and $\mathrm{Y}_{\mathrm{i}}$ the fuel/CO mass fractions. The oxygen limit, $\mathrm{Y}_{\mathrm{O} 2 \mathrm{Lim}}$, for combustion is a function of the local gas temperature [14], given as :

$$
\mathrm{Y}_{\mathrm{O} 2 \mathrm{Lim}}=\frac{\mathrm{C}_{\mathrm{p}}\left(\mathrm{T}_{\mathrm{f}}-\mathrm{T}\right)}{\Delta \mathrm{H}_{\mathrm{O} 2}}
$$

where $\mathrm{C}_{\mathrm{p}}$ is the mixture specific heat, $\mathrm{T}_{\mathrm{f}}$ the flame temperature, and $\Delta \mathrm{H}_{\mathrm{O} 2}$ heat of combustion for burning $1 \mathrm{~kg}$ oxygen. The source term is multiplied by $\mathrm{H}_{\text {eav }}\left(\mathrm{Y}_{\mathrm{O} 2}-\mathrm{Y}_{\mathrm{O} 2 \mathrm{Lim}}\right)$, where $\mathrm{H}_{\text {eav }}$ is the Heaviside unit step function, which is zero when its argument is negative $\left(\mathrm{Y}_{\mathrm{O} 2}<\mathrm{Y}_{\mathrm{O} 2 \text { Lim }}\right.$ i.e. $\mathrm{Y}_{\mathrm{O} 2} \in$ no burn range) and 1 when it is positive $\left(\mathrm{Y}_{\mathrm{O} 2}>\right.$ YO2,Lim i.e. $\mathrm{Y}_{\mathrm{O} 2} \in$ burn range). This simple flame extinction model allows to the simulation of fire growth and smoke stratification in progressively vitiated environment.

Regarding the chemical reaction time, one need only consider the first step of as being instantaneous. The second step is much greater than the first step, and the oxidation rate of $\mathrm{CO}$ is also determined from an Arrhenius expression [17],

$$
\dot{\omega}_{\mathrm{CO}, \mathrm{ARR}}=-\mathrm{A} \exp (-\mathrm{E} / \mathrm{RT})[\mathrm{CO}]\left[\mathrm{H}_{2} \mathrm{O}\right]^{0.5}\left[\mathrm{O}_{2}\right]^{0.25}
$$

This over-all rate expression (7) for carbon monoxide-oxygen reaction is established from a turbulent flow reactor in the presence of water. The local reaction rate of $\mathrm{CO}$ is crudely determined from the slower rate of the mixing rate (Equation 5) and the Arrhenius rate (Equation 7). The heat release rate is determined from the consumption rate of the two combustibles of $\mathrm{CO}$ and $\mathrm{C}_{\mathrm{m}} \mathrm{H}_{\mathrm{n}}$. This combustion model in non-premixed flames is made tractable by their inherent simplicity.

The key timescales, $\tau_{\text {mix }}$, is supposed to relate approximately to the dissipation rate as below :

$$
\tau_{\text {mix }} \approx \mathrm{C}_{\mathrm{EDC}} \frac{\varepsilon}{\mathrm{k}}
$$


In the present study, we apply the dynamic modelling method to obtain appropriate value of the coefficient $\mathrm{C}_{\mathrm{EDC}}$.

$$
\mathrm{C}_{\mathrm{EDC}}=23.6\left(\frac{v \varepsilon}{\mathrm{k}^{2}}\right)^{1 / 4} \frac{\chi}{1-\chi \gamma}
$$

where $\gamma$ is the fraction of the fluid contained within the fine structures [18].

$$
\gamma=9.7\left(\frac{v \varepsilon}{\mathrm{k}^{2}}\right)^{3 / 4}
$$

Here, $\chi$ is a factor between zero and one to express the fraction of the fine structures which can react as a function of the mixture fraction $\mathrm{Z}$.

$$
\chi=\frac{Z}{Z_{\text {st }}} \quad \text { if } 0 \leq \mathrm{Z}<\mathrm{Z}_{\mathrm{st}} \quad \text { and } \quad \chi=\frac{1-\mathrm{Z}}{1-\mathrm{Z}_{\mathrm{st}}} \quad \text { if } \mathrm{Z}_{\mathrm{st}} \leq \mathrm{Z} \leq 1
$$

where $\mathrm{Z}_{\mathrm{st}}$ is the stoichiometric mixture fraction. The dynamic modelling method in terms of $\mathrm{k}, \varepsilon$ and the kinematic viscosity $v$, allows to take into account the mass transfer rate between the fine structures and the bulk of the fluid. The heat generation resulting from the dissipation of turbulence energy is assumed to mainly occur on the resolved scale, where production and dissipation balance.

\subsection{Radiative Heat Transfer}

For a heavily sooting flame such as fire, radiation is a crucial aspect of combustion, and can dominate other modes of heat transfer. A radiative transfer equation (RTE) is solved by using a discrete expression adapted to a finite volume method [14].

$$
\vec{\nabla} \cdot \vec{\Omega} \mathrm{I}+\kappa \mathrm{I}=\kappa \frac{\sigma \mathrm{T}^{4}}{\pi}
$$

As the radiation spectrum of soot is continuous, it is assumed that the mixture of soot and gas behaves as a gray medium with a mean absorption coefficient, $\kappa$, used in RTE. For simplicity, six bands are selected to give an accurate representation of the most important radiation bands of $\mathrm{CO}_{2}$ and $\mathrm{H}_{2} \mathrm{O}$. For the calculation of the gray or band-mean gas absorption coefficient, $\kappa_{\mathrm{g}}$, a narrow-band model (RadCal) has been implemented in FDS [14]. The effect of soot concentration on radiation is included by adding the radiation coefficient of soot, $\kappa_{\mathrm{s}}$, into that of gas.

$$
\kappa=\kappa_{s}+\kappa_{g}
$$

where soot absorption coefficient is calculated as a function of the temperature, $\mathrm{T}$, and soot mass fraction, $\mathrm{Y}_{\mathrm{s}}[19]$ :

$$
\kappa_{s}=1225 \mathrm{~T} \frac{\rho Y_{\mathrm{s}}}{\rho_{\text {soot }}}
$$




\subsection{Soot Formation and Its Oxidation}

Soot production in fire plumes is a highly complex subject due to the spatially-varying formation and oxidation processes, the influence of turbulent fluctuations and strong temperature and fuel dependent effects. Nevertheless, a number of researchers [19, 20 ] have had some success in identifying factors which allow simplified analysis. In the current study, a global soot formation model is incorporated into a turbulent flow calculation in a convection-diffusion equation for the soot mass fraction.

$$
\frac{\partial \rho Y_{s}}{\partial t}+\frac{\partial\left(\rho_{u_{i}} Y_{s}\right)}{\partial x_{j}}-\frac{\partial}{\partial x_{j}}\left(\frac{\mu_{t}}{S_{c}} \frac{\partial Y_{s}}{\partial x_{j}}\right)=\dot{\omega}_{s}
$$

The soot production rate is written as :

$$
\dot{\omega}_{\mathrm{s}}= \begin{cases}\dot{\omega}_{\mathrm{f}}-\dot{\omega}_{\mathrm{o}} & \left(\mathrm{Z} \in\left[\mathrm{Z}_{\mathrm{so}}, \mathrm{Z}_{\mathrm{c}}\right]\right) \\ -\dot{\omega}_{\mathrm{o}} & \left(\mathrm{Z} \in\left[0, \mathrm{Z}_{\mathrm{so}}\right]\right)\end{cases}
$$

Two mixture fraction limits delimit the soot formation and oxidation regions. The incipient mixture fraction is $\mathrm{Z}_{\mathrm{c}}=0.15$, and the mixture fraction threshold where soot oxidation starts is $Z_{\mathrm{so}}=0.1$. The laminar point height is used to take into account the differences in sooting behaviour of different fuels. A fuel's smoke point is the maximum height of its laminar flame burning in air at which soot is not released from the flame tip. Based on a LSP (Laminar Smoke Point) concept [19, 20], soot formation is assumed to be controlled by second-order homogeneous gaseous reaction processes, and thus, is expressed as a function of the mixture fraction, $\mathrm{Z}$, and gas temperature, $\mathrm{T}$ :

$$
\dot{\omega}_{\mathrm{f}}=\operatorname{Af}_{\mathrm{f}} \rho^{2}\left(\frac{Z-Z_{s t}}{1-Z_{s t}}\right) T^{\gamma} \exp \left(-T_{\alpha} / T\right)
$$

Here $Z_{\text {st }}$ is stoichiometric mixture fraction, the temperature exponent $\gamma=2.25$ and activation temperature $\mathrm{T}_{\alpha}=2000 \mathrm{~K}$. The parameter defining the fuel's sooty propensity is the pre-exponential factor, $\mathrm{A}_{\mathrm{f}}$, which is reversely proportional to its LSP height. There is a large body of literature establishing correlations between the smoke point and soot formation for many fuels [19]. Although this approximation is incapable of accurately reproducing soot surface growth, it should be capable of capturing global trends for use in engineering calculations of radiation and visibility during fire development.

The soot oxidation in Equation 16 is assumed to proceed through a single reaction step,

$$
\mathrm{C}_{\mathrm{s}}+\mathrm{O}_{2} \rightarrow \mathrm{CO}_{2}
$$

In turbulent flame, there remain some approximations due to turbulence interactions. By assuming that the mixing time in sub-grid scale is the limiting mechanism, the specific rate of soot oxidation in turbulent flame is expressed by an EDC approach [15].

$$
\dot{\omega}_{\mathrm{o}}=\rho \tau_{\text {mix }} \min \left(\mathrm{Y}_{\mathrm{s}}, \frac{\mathrm{Y}_{\mathrm{O} 2}}{v_{\mathrm{s}}}\right)
$$


where $v_{\mathrm{s}}$ denotes the stoichiometric coefficient for burning $1 \mathrm{~kg}$ of soot. This approximation contains no chemically kinetic mechanism to suppress homogeneous soot formation by $\mathrm{O}_{2}$.

\section{RESULTS AND DISCUSSION}

Two basic types of experiments, such as free pool and enclosure fires are largely studied by the fire security community. For a free pool-like fire, it is relatively easy task for obtaining experimental data, allowing a detailed comparison between prediction and experiment. Then, a reduced scale enclosure fire configuration is chosen to continue the validation of the current model. Simulations are performed on a multi-processor Linux cluster available at the Institut P' of Poitiers, using the parallel MPI [14].

\subsection{Free Pool-Like Fire}

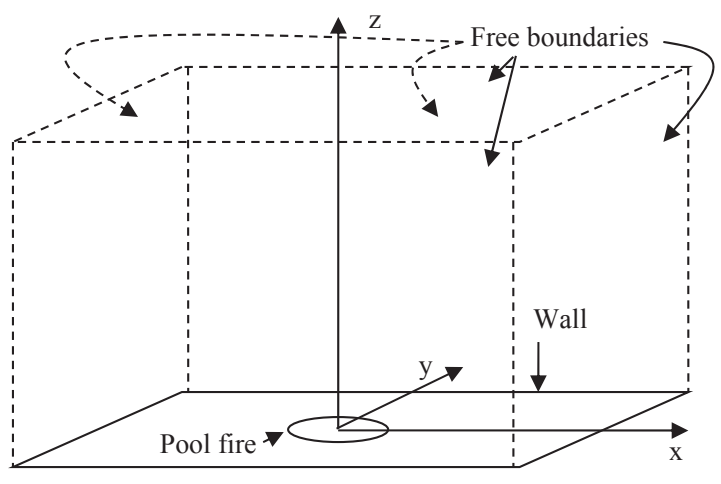

Figure 1 Schematic diagram of the release examined experimentally and the coordinate system

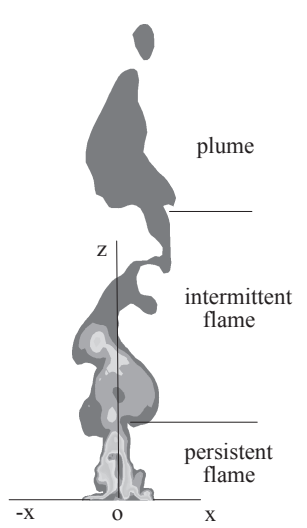

Figure 2 Instantaneous temperature output from LES

Here we concentrate on a comparison of the simulation predictions with the detailed measurements of the flame and flow structures [21] for $30.5 \mathrm{~cm}$ methanol pool fire, as shown in Figure 1. The flame is stabilized on a horizontal circular liquid fuel, providing a heat release rate $(\mathrm{HRR})$ of $24.6 \mathrm{~kW}$. The free boundaries are located sufficiently far away from the fire to minimize a numerical perturbation. The 3D computational domain are $0.6 \mathrm{~m} \times 0.6 \mathrm{~m} \times 1.8 \mathrm{~m}$ in the $\mathrm{x}, \mathrm{y}$ and $\mathrm{z}$ directions, respectively. The accuracy of LES depends on filtering scale related to mesh size, and thus grid refinement studies were performed by using two grid system containing $30(\mathrm{x}) \times 30(\mathrm{y}) \times 90(\mathrm{z})$ named as Mesh1 and $40(\mathrm{x}) \times 40(\mathrm{y}) \times 120(\mathrm{z})$ cells as Mesh2. Cell sizes are uniform, and 2 to $1.5 \mathrm{~cm}$ by using Mesh 1 and 2, respectively.

The calculated characteristics of the instantaneous temperature output on the middle plane is plotted in Figure 2. For a low Froude number flame, shear-stresses between hot combustion products and fresh air make the flow unstable and amplify oscillations 
near the fire base due to air entrainment variation and flame flicker, inducing large eddy structures corresponding to hot gases puffs burning. Fresh air entrained by these vortexes feeds the flame with oxygen and cools the smoke influencing natural convection and then air entrainment. Three regions of the pool fires are numerically reproduced. At the flame base, immediately above the burner surface, is the persistent flame zone, which appears to have a constant shape and structure. This zone is followed by the intermittent zone that has a fluctuating character due to buoyant instability. In this region, ambient air is sucked into the flame from a downstream location, creating a large recirculating zone above the horizontal burner. The last region is the plume zone that is non-reacting and turbulent, giving a good idea of the flow development and the boundary layer broadening. Becker [22] has demonstrated that, in the natural convection limit, as the Froude number decreases, coherent structures appear in the reactive zone above a horizontal burning surface, the flame presenting a pronounced instability due to buoyancy. Globally, the approach of LES is capable of reproducing the mechanism generating the buoyant instability present in the early development of the flame and the transition to turbulence far away from the fire source.

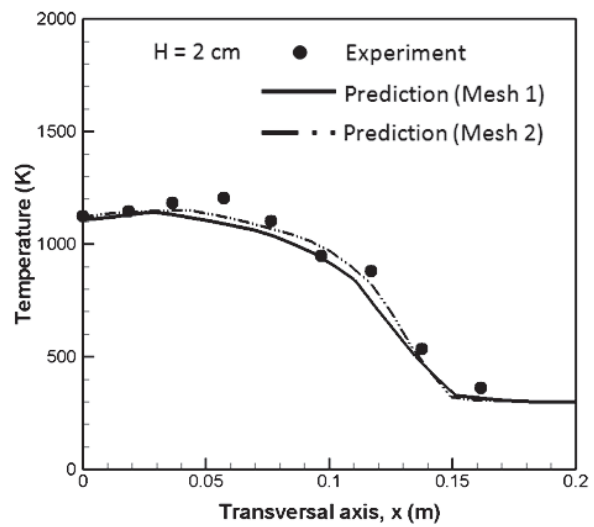

Figure 3 Influence of the grid size on the mean temperature at a height of $2 \mathrm{~cm}$

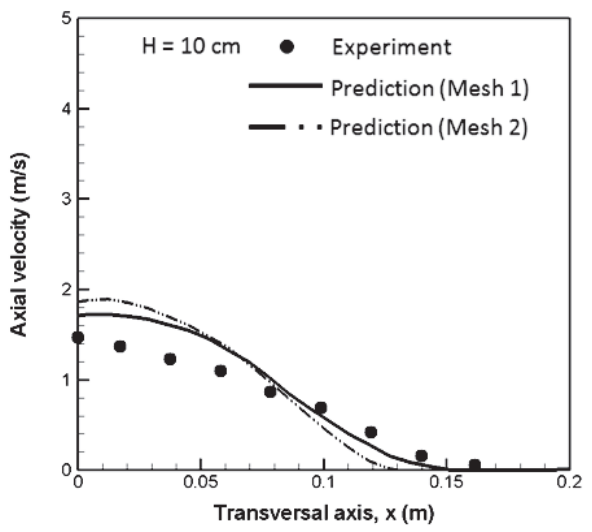

Figure 4 Influence of the grid size on the mean axial velocity at a height of $10 \mathrm{~cm}$

Influence of number of grid cells (Mesh 1 and 2) on the predicted values is checked for a heat release rate of $24.6 \mathrm{~kW}$. The mean temperature and axial velocity versus radial position at $\mathrm{H}=2$ and $10 \mathrm{~cm}$ above the pool fire are shown in Figures 3 and 4 . The position and value of the peak temperature are accurately predicted by the numerical model. The changes between the coarse $(2 \mathrm{~cm})$ and fine $(1.5 \mathrm{~cm})$ meshs in the calculated plots of temperature and velocity above the fire source base are less than $5 \%$. These LES computations are practically grid independent in spite of relatively coarse grid resolution of $2 \mathrm{~cm}$ for the fire plume. 


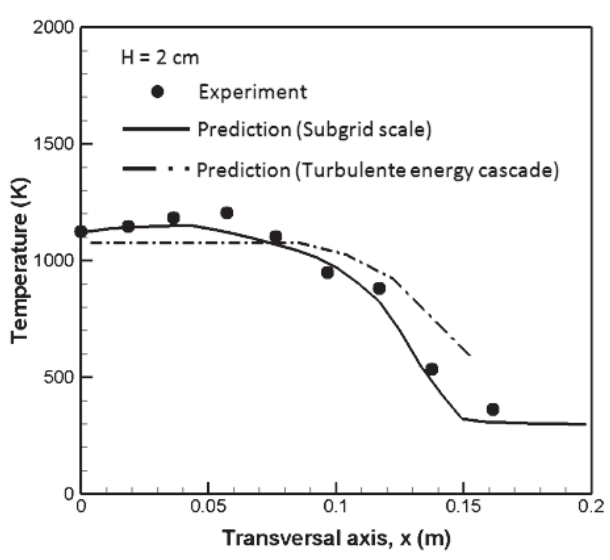

Figure 5 Comparison of the predicted mean temperature to the experimental data at a height of $2 \mathrm{~cm}$

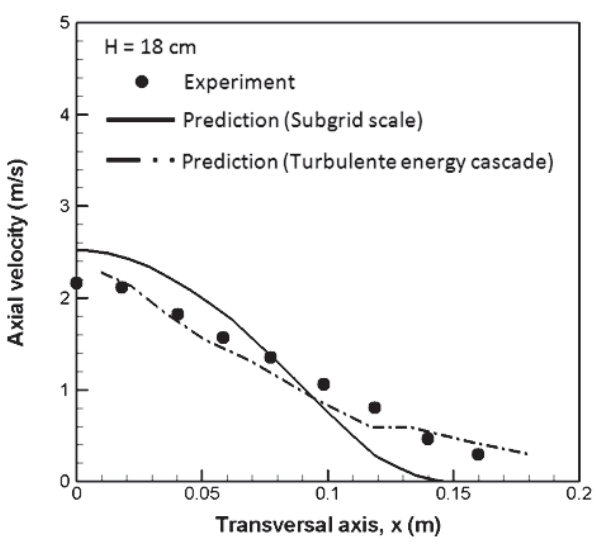

Figure 7 Comparison of the predicted mean axial velocity to the experimental data at a height of $18 \mathrm{~cm}$

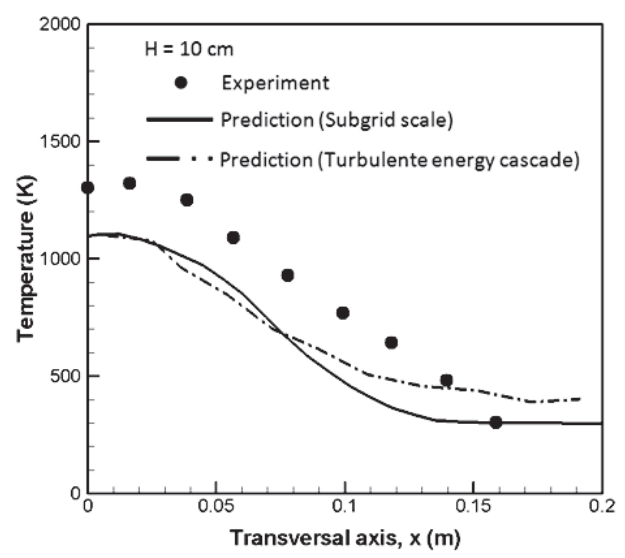

Figure 6 Comparison of the predicted mean temperature to the experimental data at a height of $10 \mathrm{~cm}$

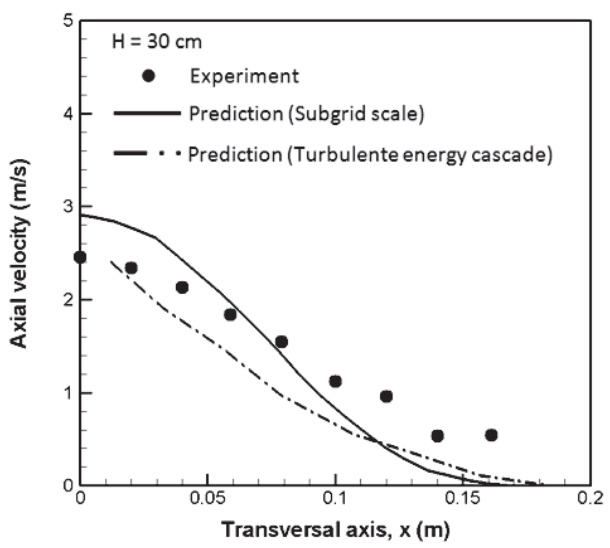

Figure 8 Comparison of the predicted mean axial velocity to the experimental data at a height of $30 \mathrm{~cm}$

In work of Chen [15], the reaction rate is derived according to turbulent energy cascade concept in the EDC framework. In the current turbulent combustion model, the reaction rate is derived solely from the subgrid scale in EDC. The comparison of model predictions with experimental data allows to establish what constitutes a sufficiently accurate prediction. The profiles of the mean temperature and the axial velocity versus radial position at $\mathrm{H}=2,10,18$ and $30 \mathrm{~cm}$, obtained from the two approaches are compared with the experimental data in Figures 5-8. At lower part flame $(\mathrm{H}=2 \mathrm{~cm}), \mathrm{EDC}$ based on the cascade concept [15] under-predicts the temperature by around $200 \mathrm{~K}$, far away from the centreline. This may be attributed to the under-prediction of the mixing rate by the EDC because turbulence is not fully developed in this region. The calculated maximum values from the current model are in good agreement with experiments. 
The predicted peak in temperature moves inward radially at the pool centreline as the experimental trend. This suggests that the location of a thin flame sheet where the peak temperature occurs, is controlled by the stoichiometry of the reactants rather than complex Kolmogorov time scale that govern premixed flames. The study of Baum [23] also confirm that in most fires, the primary momentum transport of turbulent diffusion flame is sustained by large-scale energy-containing eddies which are related to a typical geometry characteristic of a pool fire. It is found that the combustion model fails to give satisfactory predictions in upper part flame $(\mathrm{H}=10 \mathrm{~cm})$. The Smagorinsky sub-grid model is known as being too dissipative, particularly for an insufficient grid refinement in the plume region. Besides, such a pulsing behaviour makes also accurate measurements difficult. It seems most likely that the discrepancies are due to a combination of the experimental uncertainties and the possible error in the numerical simulation. The predicted axial velocity profiles agree well with the measurements along the height. The velocity is relatively low near the edge of the horizontal burner surface, due to very low upward gas velocities. Far away from the pool fire surface, buoyancy effects become important and the flow is strongly upward accelerated, leading to an increase of the axial velocity with height.

Orloff [10] performed detailed measurement only for the chemical species, such as $\mathrm{O}_{2}, \mathrm{CO}, \mathrm{CO}_{2}, \mathrm{H}_{2} \mathrm{O}$ and soot from a low Froude number propane and propylene free pool fire of $178 \mathrm{~kW}$ by using a porous burner of $0.75 \mathrm{~m}$ in diameter. However, the measured temperature and velocity fields from such fire are not available. McCaffrey [24] performed detailed measurement and dimensional analysis of temperature and velocity using a square methane burner of $0.3 \times 0.3 \mathrm{~m}^{2}$ for a heat release rate varying from 15 to $60 \mathrm{~kW}$. Based on the experimental data, some relations were established by dividing the fire into three regions, such as a zone of luminous persistent flame, an intermittency combustion region and a non-reacting buoyant plume characterized by decreasing velocity and temperature with height. Based on the fire characteristic length, a grid system containing $70(\mathrm{x}) \times 70(\mathrm{y}) \times 100(\mathrm{z})$ with uniform cell sizes of $2 \mathrm{~cm}$ is chosen in the numerical simulation. Profiles of the predicted gas temperature rise and vertical velocity along the centerline from the burner surface is compared with McCaffrey's correlation [24] in Figures 9 and 10, and a good agreement between the prediction and the McCaffrey's correlation is obtained. 


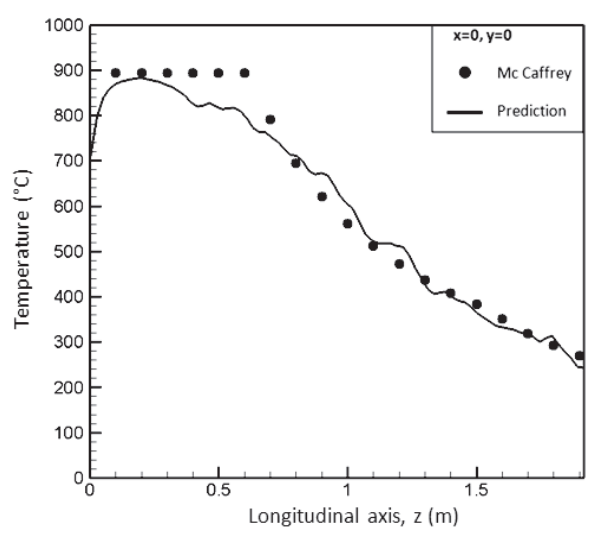

Figure 9 Comparison of the predicted mean centreline temperature to McCaffrey's correlation

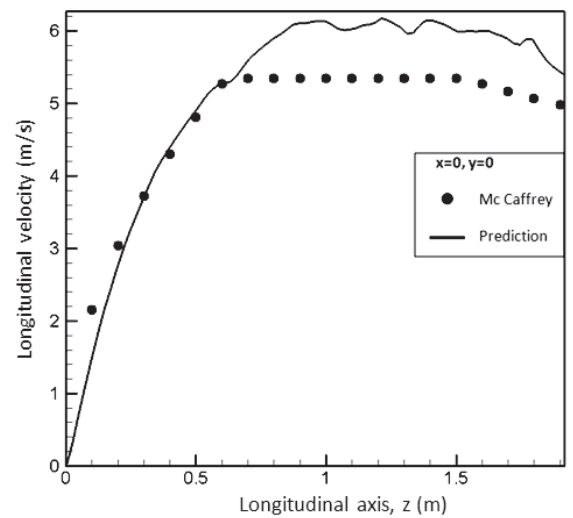

Figure 10 Comparison of the predicted mean axial velocity to McCaffrey's correlation

The predicted time-averaged species from FDS6 and the current model are compared with the experimental data from this propane pool fire [10]. Evident in Figures 11-16 for species as $\mathrm{O}_{2}, \mathrm{CO}_{2}$ and $\mathrm{H}_{2} \mathrm{O}$ versus radial position at $\mathrm{H}=5.2$ and $12 \mathrm{~cm}$ is a good agreement between the predicted and the measured species in radial traverse, surrounding the cone of fuel gas immediately above the burner base. Figures 17-18 show the profiles for the mean mass fraction of the chemical species $\mathrm{O}_{2}$ and $\mathrm{CO}_{2}$ along the centerline. The $\mathrm{CO}_{2}$ appears to be approximately proportional to the oxygen depletion in the reacting region. It can be seen that the quality of the agreement between the prediction and the experiment deteriorates for $\mathrm{O}_{2}$ and $\mathrm{CO}_{2}$ along the centerline in the plume region. The experimental data show that a zone with $\mathrm{CO}_{2}$ develops and sharply disappears as we move away from the cone of fuel vapour. Maximum scatter is found at peak $\mathrm{CO}_{2}$ concentration, and at maximum $\mathrm{O}_{2}$ depletion far away from the pool fire surface. Subsequent variations of the measured $\mathrm{O}_{2}$ take place in the nonreacting buoyant plume region due to turbulent mixing between product species and air entrainment from outside of the plume boundary. A strong mixing between the products and air in the plume region, probably resulting from a convective type of mixing rather than from a diffusive one, is not correctly simulated by using both FDS6 and the current model. 


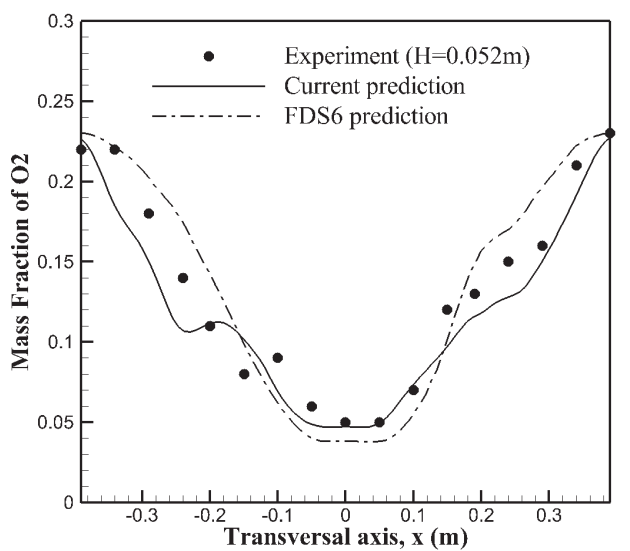

Figure 11 Comparison between the measured and predicted mean oxygen mass fraction at a height of $0.052 \mathrm{~m}$

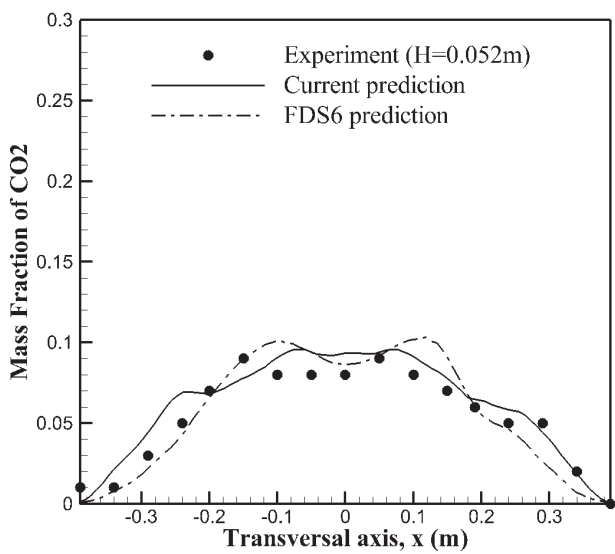

Figure 13 Comparison between the measured and predicted mean $\mathrm{CO}_{2}$ mass fraction at a height of $0.052 \mathrm{~m}$

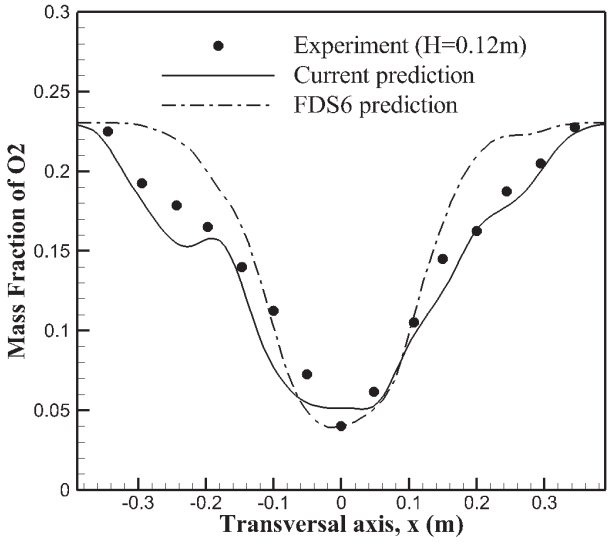

Figure 12 Comparison between the measured and predicted mean oxygen mass fraction at a height of $0.12 \mathrm{~m}$

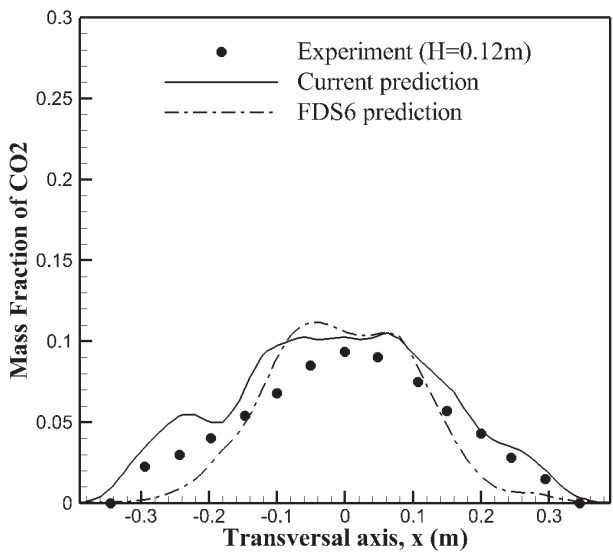

Figure 14 Comparison between the measured and predicted mean $\mathrm{CO}_{2}$ mass fraction at a height of $0.12 \mathrm{~m}$ 


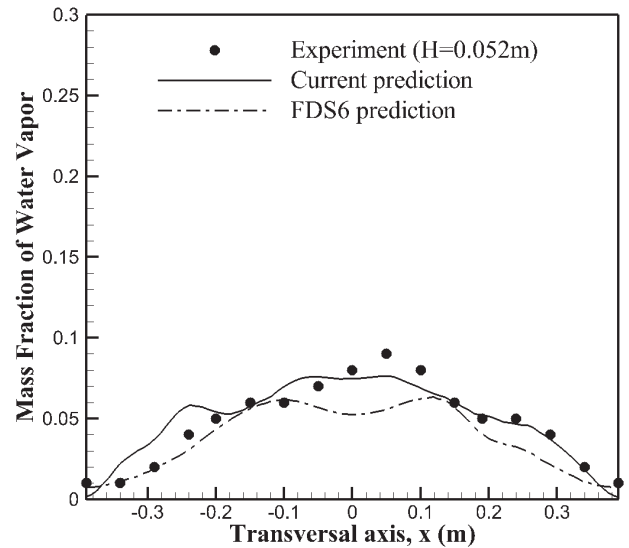

Figure 15 Comparison between the measured and predicted mean water vapour mass fraction at $H=0.052 \mathrm{~m}$

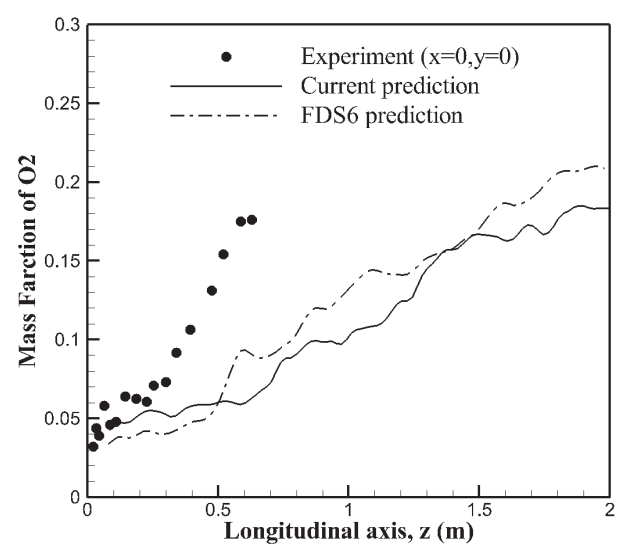

Figure 17 Comparison between the measured and predicted mean oxygen mass fraction at the centreline

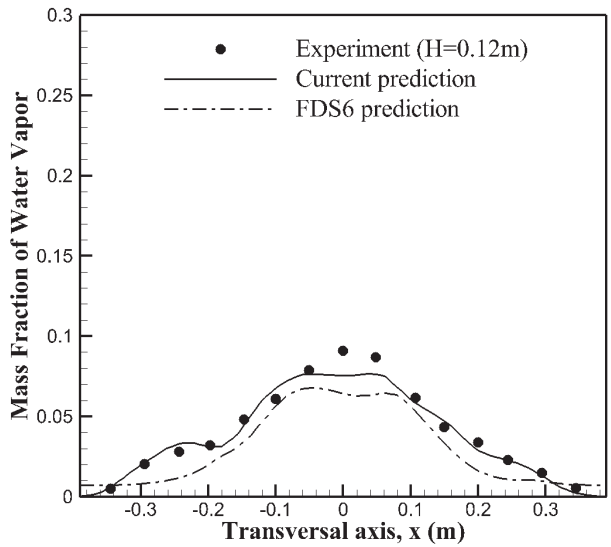

Figure 16 Comparison between the measured and predicted mean water vapour mass fraction at $H=0.12 \mathrm{~m}$

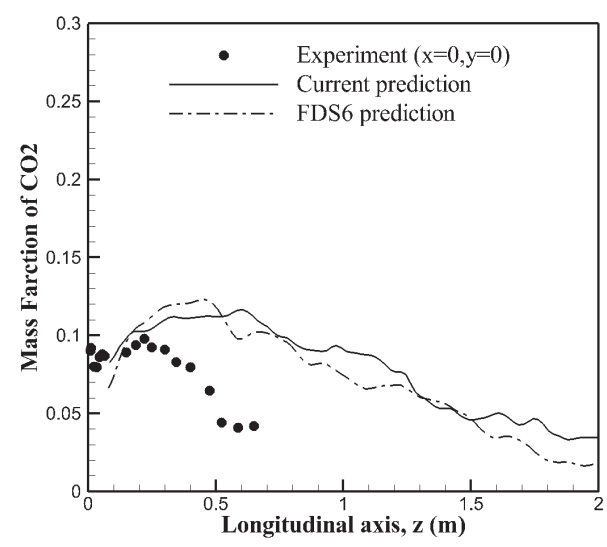

Figure 18 Comparison between the measured and predicted mean $\mathrm{CO}_{2}$ mass fraction at the centreline

The predicted CO molar fraction from FDS6 and the current model in a traverse versus radial position at $\mathrm{H}=5.2 \mathrm{~cm}$ and along the centreline against the average mixture fraction, Z, is plotted in Figure 19. The magnitude of CO is well predicted by using the current model, and the computed profiles exhibit the same similarity that is observed experimentally. The peak in the carbon monoxide is predicted just inside the flame, and CO declines significantly by using FDS6 far away from the fire source, i.e., in the fuellean region. Turbulent mixing and fluctuations reduce the peak of $\mathrm{CO}$ concentrations as compared to that in laminar diffusion flames [10]. Both the experiment and prediction show that local concentration of $\mathrm{CO}$ in the fire is correlated approximately as a function 
of mixture fraction because such buoyant turbulent diffusion flames generally have modest stretch rates. The soot volume fraction versus radial position in two traverse at $\mathrm{H}=5.2$ and $12 \mathrm{~cm}$ above the propylene pool fire is shown in Figures 20 and 21. Given in Figure 22 is the soot volume fraction along the centreline against the mixture fraction. The predicted profiles of soot volume fraction from the current model show a high degree of similarity with the measured ones only close to the fuel-rich condition $(\mathrm{Z}>0.1)$. This implies that soot formation is likely subject to precursors, consistent with the hypothesis that the smoke point is the controlling parameter for soot formation. Past the flame tip, a significant amount of soot in the experimental flame [10] is not computed, particularly under the fuel-lean condition $(\mathrm{Z}<0.1)$. Besides, the influence of turbulent fluctuations, strong temperature and fuel dependent effects on soot surface growth can not be captured by the smoke-point concept in its present form. This helps explain the limited success of smoke-point attempts to predict soot emissions in fuel-lean conditions. By using FDS6 with a soot yield of 0.008 , soot formation occurs more quickly in the simulation than in the experiment in the fuel-rich region near the fire source, causing a significant amount of soot to be sustained there. This indicates that the soot model in FDS6 for the spatially-varying soot oxidation process needs adjustment.

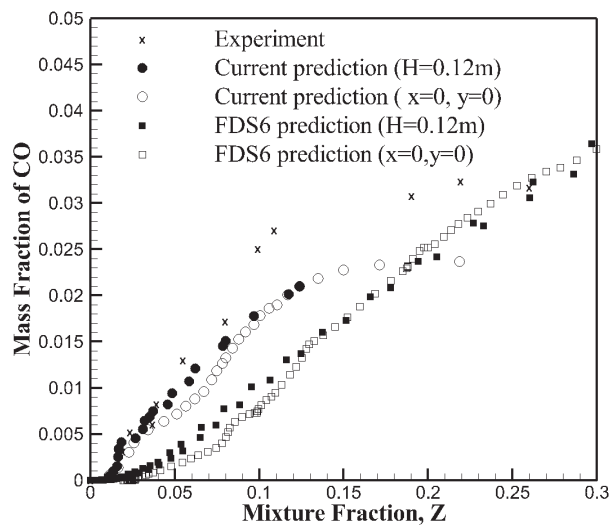

Figure 19 Comparison between the measured and predicted $C O$ mass fraction as a function of the average mixture fraction

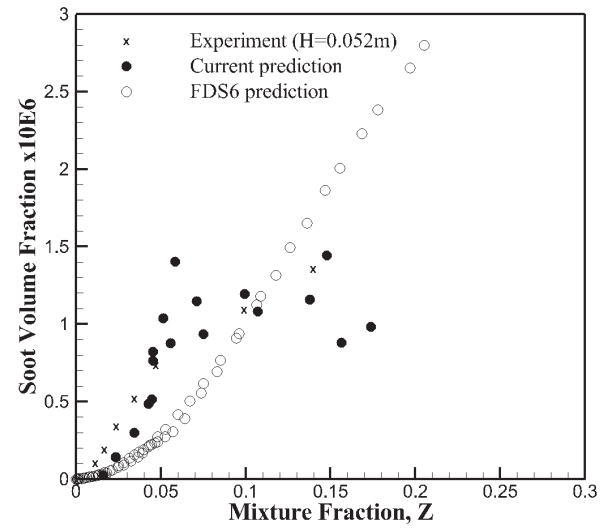

Figure 20 Comparison between the measured and predicted soot volume fraction as a function of the average mixture fraction at a height of $0.052 \mathrm{~m}$ 


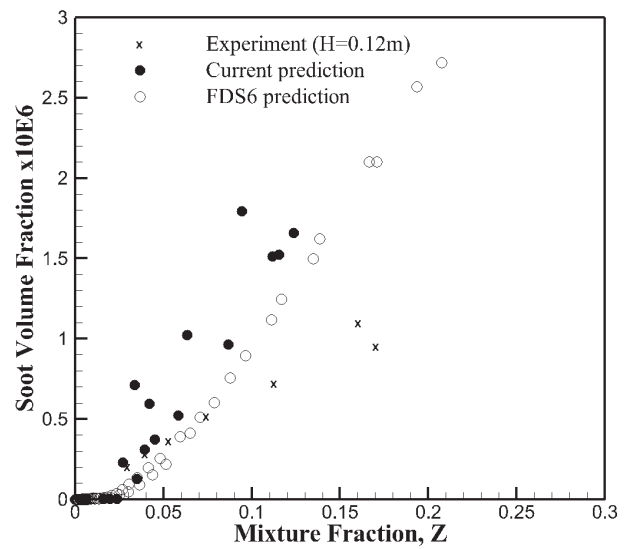

Figure 21 Comparison between the measured and predicted soot volume fraction as a function of the average mixture fraction at a height of $0.12 \mathrm{~m}$

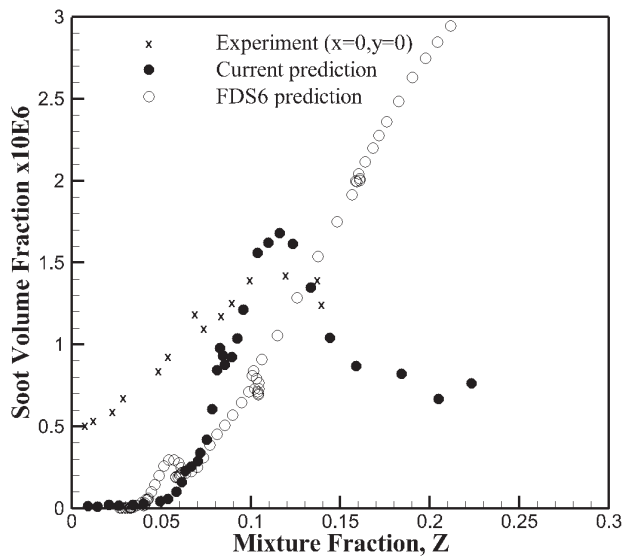

Figure 22 Comparison between the measured and predicted soot volume fraction as a function of the average mixture fraction at the centreline

\subsection{Enclosure Fire}

The schematic diagram of the fire configuration examined experimentally by NIST [11], the coordinate system and the enclosure geometry $(\mathrm{H}=1 \mathrm{~m}, \mathrm{~W}=1 \mathrm{~m}$ and $\mathrm{L}=1.4 \mathrm{~m})$ are shown in Figure 23. The experimental setup box is $1 / 3$ of the standard ISO room with a doorway of $\mathrm{h}=0.8 \mathrm{~m}$ in height and of $\mathrm{w}=0.5 \mathrm{~m}$ in width. A horizontal square burner with an area of $0.4 \times 0.4 \mathrm{~m}^{2}$ was mounted on a floor level at the centre of the enclosure, allowing burning of the fuel as heptane. The wall, ceiling and floor were constructed from an insulating material.

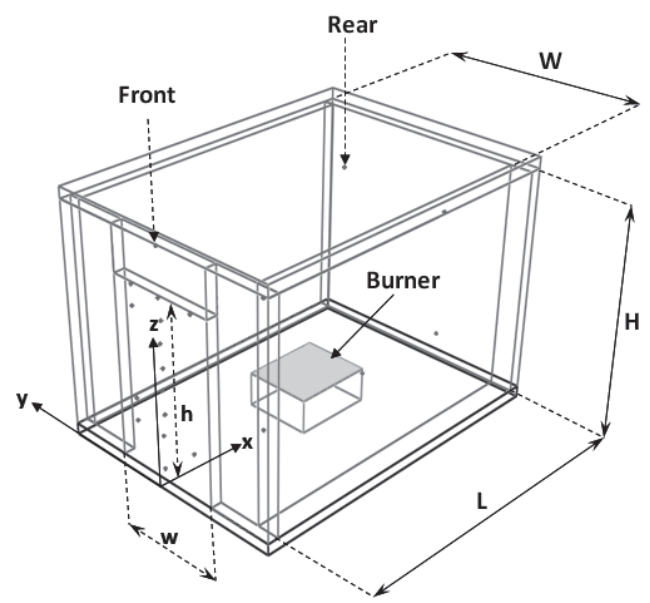

Figure 23 Schematic diagram of the enclosure fire examined experimentally and the coordinate system in the numerical simulation 
In the numerical simulations, an extended region measuring $2 \mathrm{~m} \times 1.2 \mathrm{~m}$ in plane $\mathrm{x}^{-} \mathrm{y}$, and $1.6 \mathrm{~m}$ in height $(\mathrm{z})$ is used. For this enclosure fire, an adequate resolution of the fire plume can be achieved with a spatial resolution of about $4 \mathrm{~cm}$ from an uniform grid system containing $50(\mathrm{x}) \times 30(\mathrm{y}) \times 40(\mathrm{z})$. CPU times were of the order of 5 days for a real 75 minutes simulation in transient mode. Duration of the fire propagation due to fire growth is always too short ( $20-40$ seconds) to take the measurements of temperature, velocity and heat fluxes by means of thermocouples, Laser Doppler Velocimetry system and fluxmeters. There are still very few experimental data available from an enclosure fire due to the high cost and the instrumentation difficulty. The temperature, the volume fraction of the chemical species as $\mathrm{O}_{2} / \mathrm{CO}_{2}$ and the soot mass fraction are measured in transient mode only in two points through the probes close to the front door and the rear wall. Five probes are also vertically placed on the centreline of the front door to measure the normal velocity at a height of 5, 20, 40, 60 and $80 \mathrm{~cm}$ above the floor.

In the experiments [11], the opening size was fixed and the equivalence ratio was varied by changing the mass flow rate of the fuel, giving a theoretical heat release rate (HRR) varying from 80 to $350 \mathrm{~kW}$. The maximum theoretical HRR inside the enclosure can be derived by multiplying the ventilation controlled mass inflow of air by the energy released per kilogram of air completely consumed inside. For such enclosure fire, the peak in theoretical HRR calculated from $\mathrm{Q}_{\max }=3000 \mathrm{x} 0.5 \mathrm{Ah}^{1 / 2}(\mathrm{~kW})[5]$ where $\mathrm{A}\left(\mathrm{m}^{2}\right)$ and $\mathrm{h}(\mathrm{m})$ are area and height of the doorway respectively, is equal to $530 \mathrm{~kW}$. As an illustration, evolution of the calculated HRR by using the measured mass loss rate of the fuel is compared with the theoretical one in Figure 24. Such enclosure fire is ensured by abundant oxygen from air entrainment at the doorway because the heat release rate is below $530 \mathrm{~kW}$, and as a consequence, the calculated HRRs from FDS6 and the current model approach the theoretical one, implying a practically complete combustion.

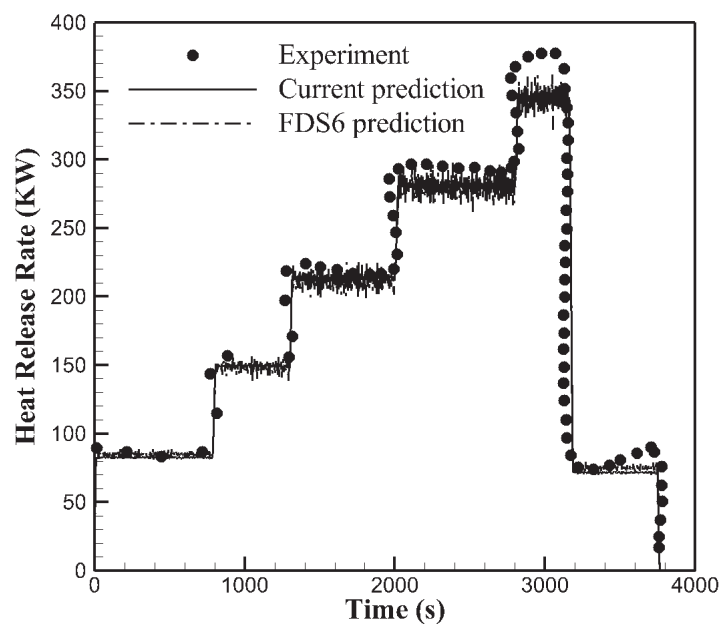

Figure 24 Evolution with time of the theoretical and calculated Heat Release Rate 
A progressive increase of the heat release rate is characterized by a development of external burning due to fire extent growth. The flame propagation is analysed by examining the contours of the temperature (cf. Figure 25) and the $\mathrm{CO}$ mass fraction (cf. Figure 26). For a heavily sooting heptane flame, the visible flame shape corresponds to the zone where the gas temperature is higher than $500^{\circ} \mathrm{C}$. There is quasi-steady split burning characterized by the two regions of the flame, one inside the box near the fuel source, and the other one outside the box. It should be noted that only a qualitative agreement with the measured $\mathrm{CO}$ is achieved by the numerical model as a function of the HRR. The greatest source of scatter for the prediction of the amplitudes of CO close to the front door and the rear wall originates from the inherent complexity of the stratified layer flow recirculation inside the enclosure fire.

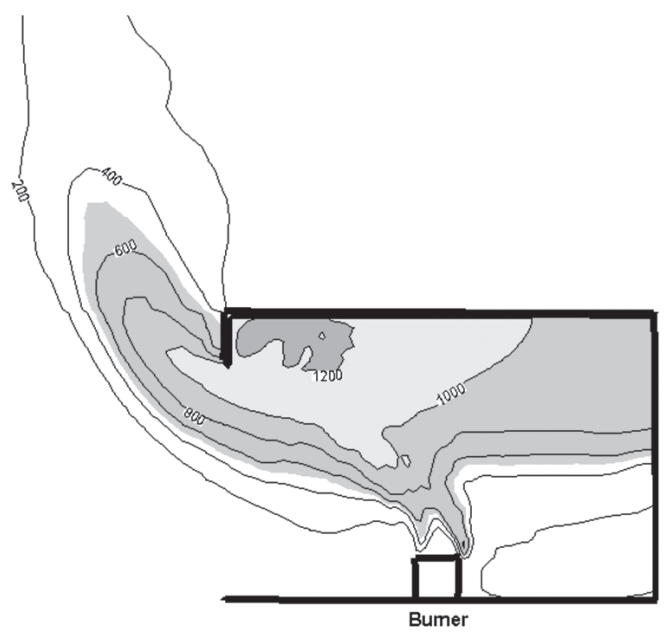

Figure 25 Contours of the temperature $\left({ }^{\circ} \mathrm{C}\right)$ at the external burning stage after the flame exhaust inside the enclosure

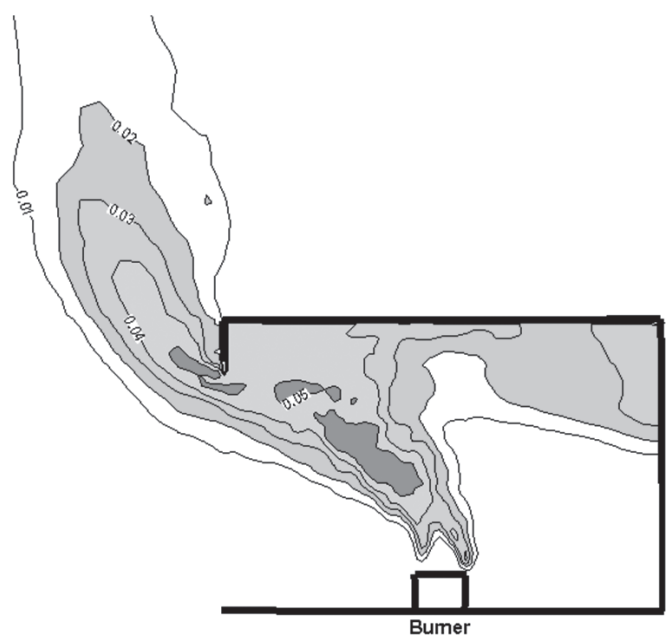

Figure 26 Contours of the CO mass fraction at the external burning stage after the flame exhaust inside the enclosure 
The temperature at the front probe versus the HRR during the fire is presented in Figure 27. When the HRR is small, the flame is attached to the burner base, corresponding to fuel controlled fire, and the hottest gases with a temperature level of $500^{\circ} \mathrm{C}$ from the combustion products are ejected through the opening. Globally, the temperature continues to increase steadily up to $1200^{\circ} \mathrm{C}$ with the $\mathrm{HRR}$ due to increase in the flame size until it attains a quasi-steady state once the external flame takes place. The predicted temperature trend from both FDS6 and the current model versus the HRR is consistent with the measured one [11].

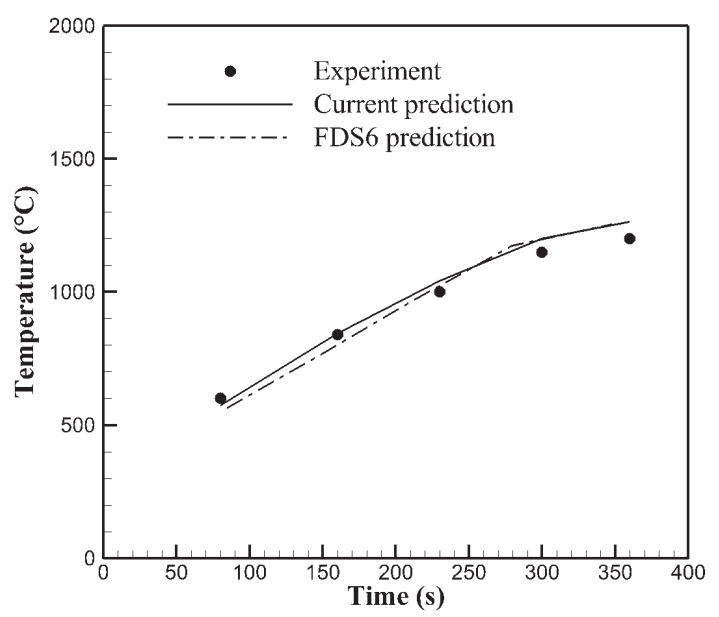

Figure 27 Temperature at the front probe as a function of the heat release rate

The normal velocities measured and predicted from FDS6 and the current model near the doorway from the vertical probes for the HRR of 80 and $300 \mathrm{~kW}$ are plotted in Figure 28. Both the prediction and measurement indicate that the processes of air entrainment into the enclosure are enhanced with an increase of the HRR through a buoyant vertical acceleration of the thermal plume and formation of a ceiling jet in the enclosure, which later spills over the opening. A stratified two layer flow in the opening region is numerically reproduced, and the position of the neutral plane is well distinguished. This implies that the enclosure is only partly filled with hot gases, collected under the ceiling, and the temperature forms a two-layer profile. Air is being entrained into the enclosure only from one half of the opening area and the hotter gas is ejected through the upper part of the opening due to the thermal expansion. The peak in the velocity of the entrained air at lower part of the opening is approximately $1 \mathrm{~m} / \mathrm{s}$, practically independent of the heat release rate. While the peak in the velocity of the ejected hotter gas from the upper part of the opening increases from 3 to $6 \mathrm{~m} / \mathrm{s}$ with an increase of the HRR from 80 to $300 \mathrm{~kW}$. It seems that the ejected mass flow rate from the enclosure is in terms not only of the opening geometry, but also of the complicated multistage process of an enclosure fire. A simple expression [5], which is based only on the opening area to specify the mass rate of air inflow, may not be appropriated. 


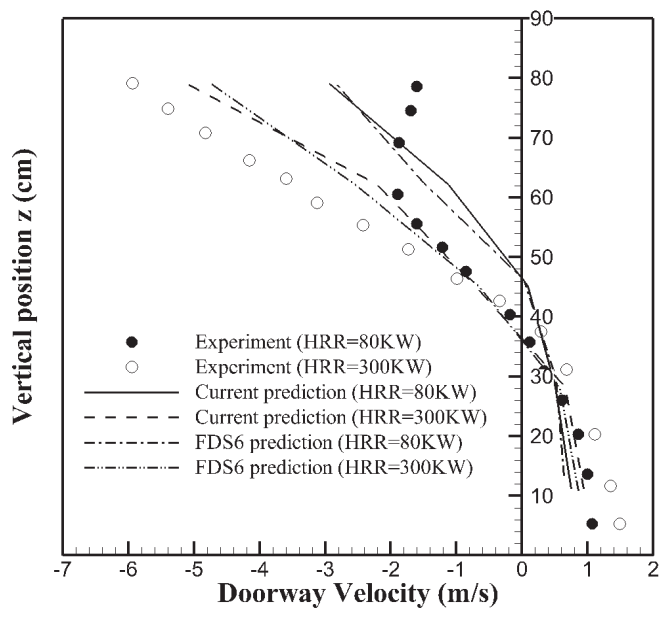

Figure 28 Normal velocity of the entrained air at the doorway for HRRs of 80 and $300 \mathrm{~kW}$

The transient histories of the oxygen, $\mathrm{CO}_{2}$ molar fraction and soot mass fraction at the front and rear probes are respectively presented in Figures 29-32. A relatively good agreement between the prediction from FDS6/the current model and the experiment for the examined chemical species as $\mathrm{O}_{2}$ and $\mathrm{CO}_{2}$ is observed. The calculated oxygen mole fraction presents the oscillations with time mainly due to the coherent periodic oscillations of the flame arising from air entrainment in a cyclic manner due to buoyancy. At the initial fire growth stage, the flame is attached to the burner base, corresponding to fuel controlled fire, and there is sufficient oxygen available for the CO oxidation into $\mathrm{CO}_{2}$. The oxygen starvation begins and the oxygen-lean, fuel-rich hot upper layer is being formed due to the excessive pyrolysis products near the fire source. Amplitudes of the $\mathrm{CO}_{2}$ production vary strongly from one cycle to another, and their maximum levels increase with the heat release rate due to development of the external flame. The reactants dilute in the enclosure, and this is accompanied by a rapid rise of the soot level at the rear wall due to increase in the equivalence ratio. Evolution of the soot formation with HRR is practically reproduced by the current model. However, as observed for the free pool like fire (cf. Figure 22) in the fuel-rich condition, soot production is significantly over-predicted by using FDS6 due to lack of the soot oxidation process. 


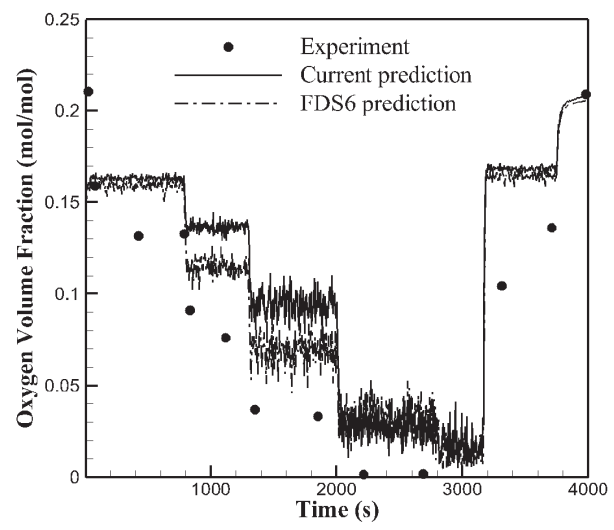

Figure 29 History of the oxygen volume fraction at the front probe

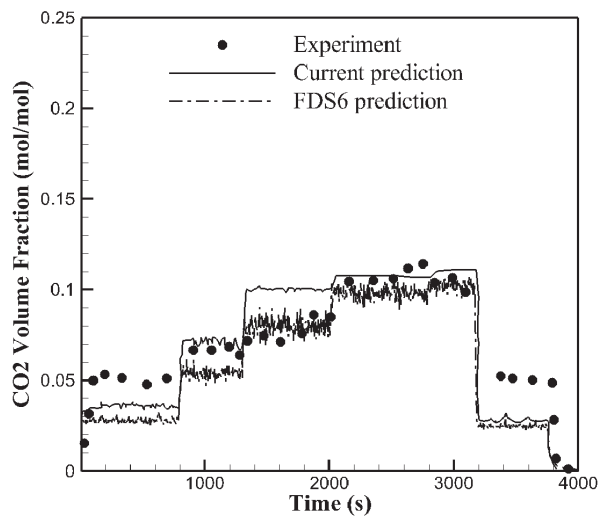

Figure 31 History of the carbon dioxide volume fraction at the rear probe

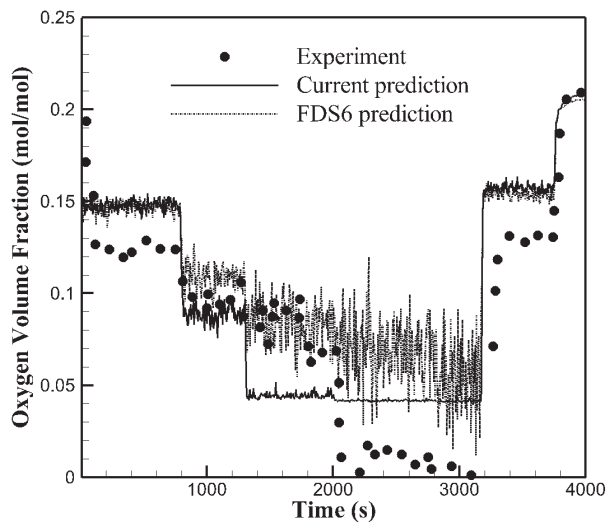

Figure 30 History of the oxygen volume fraction at the rear probe

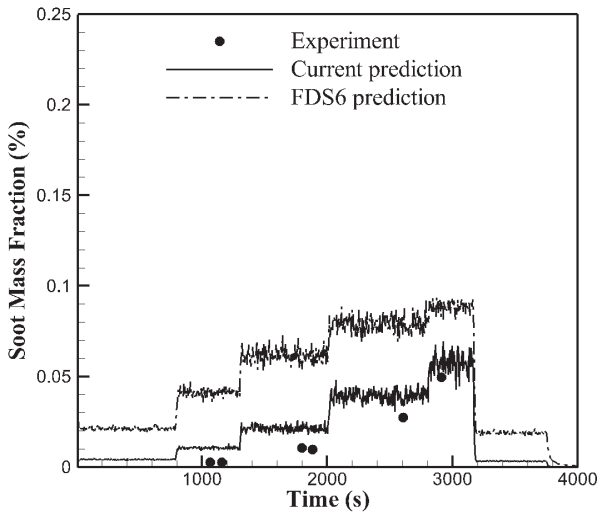

Figure 32 History of the soot mass fraction at the rear probe

\section{CONCLUSION}

This current model presents a promising alternative to account for solely the phenomena essential for obtaining sufficiently accurate predictions of dynamic/thermal fields and chemical species in non-premixed turbulent flames. Simplicity is achieved by the recognition that reaction in pool-like fire is controlled by the diffusion of oxygen into the reactive zone in a resolved scale rather than being limited by Kolmogorov time scale. Both the prediction and the experiment show that concentration of $\mathrm{CO}$ for turbulent buoyant fire in intermediate scale is well correlated with mixture fraction, and the fuel smoke point correlates the release of soot. For the present purpose, the grid system chosen from the fire characteristic length offered the best tradeoff between accuracy and cost, which is particularly useful for large scale fire in engineering calculations. 
However, a large flame extent can not be correctly predicted by the model due to buoyant instabilities at the base of the fires.

Further work is underway for a transient fire growth and a progressive vitiation of the ambient medium with self-sustained condensed fuel fire development. Because it is ensured that the flame radiation owing to pyrolysis gases and soot are properly modelled. The critical fuel supply rate needed for flame to exhaust depends on enclosure geometry, opening geometry, type of fuel as well as location of pyrolysis zone. The dominant factors which are responsible for fire evolution scenarios, such as the onset and development of a backdraft when fresh air flow goes fast into the enclosure and ignites the fuel excess after flame exhaust, should be identified.

\section{REFERENCES}

1. V. Babrauskas and Vetal. A methodology for obtaining and using toxic potency data for fire Hazard analysis. Fire Safety J. 1998; 31:345-358.

2. A.V Chamchine, Graham TL, Makhviladze GM. Experimental studies of underventilated combustion in small and medium-scale enclosures. Proceedings of the Fourth International Seminar on Fire and Explosion Hazards 2003; 97-107.

3. H. Akihiko, Yuji H, Yoshihiko H, Masashi Y. Mechanism for the upward fire spread through balconies based on an investigation and experiments for a multi-story fire in high-rise apartment building. Proceedings of the Sixth International Symposium on Fire Safety Science 1999; 649-660.

4. T. Yamada, Takanashi K. An experimental study of ejected flames and combustion efficiency. Proceedings of the Seventh International Symposium on Fire Safety Science 2002; 903-914.

5. M. A. Delichatsios, Gordon WHS, Liu X, Delichatsios M, Lee Y. P. Mass pyrolysis rates and excess pyrolysate in fully developed enclosure fires. Fire Safety Journal 2004; 39:1-21.

6. G. Cox, Kumar S. Field modelling of fire in forced ventilated enclosures. Combust. Sci Technol 1987; 52:7-23.

7. G.H. Yeoh, Yuen RKK, Lo SM, Chen, DH. On numerical comparison of enclosure fire in multi-compartment building. Fire Safety Journal 2003; 38:85-94.

8. D.T. Gottuk and Rohy, R.J. and Beyler C.I., Study of carbon monoxide and smoke yields from compartment fires with external burning. 24th Symposium (international) on Combustion (Pittsburgh: The Combustion Institute), pp.17291735 .

9. U.O. Koylu and Faeth M. Carbon monoxide and soot emissions from liquid fuelled buoyant turbulent diffusion flames. Combustion and Flame, 1991; 87:61-76.

10. L. Orloff, J. de Ris and M.A. Delichatsios. Chemical effects on molecular species concentrations in turbulent fires. Combustion and Flame, 1987; 69:273-289. 
11. B. Matthew, Anthony Hamins, Erik L. Johnsson, Sung Chan Kim, Gwon Hyun Ko and David B. Lenhert. Mesurement of Heat and Combustion Products in ReduceScale Ventilation Limited Compartment Fire. NIST Technical Note 1483.

12. Z. Wen, Yun, S., Thomson, M.J. and Lightstone, M.F. Modeling soot formation in turbulent kerosene/air jet diffusion flames," Combustion and Flame, 2003; 135, pp.323-340.

13. P. Dagaut and Nicolle, A. Experimental and detailed kinetic modeling study of the effect of exhaust gas on fuel combustion: Mutual sensitization of the oxidation of nitric oxide and methane over extended temperature and pressure ranges. Combustion and Flame, 2005; 140, pp.161-171.

14. K. McGrattan, Fire Dynamics Simulator - Technical Reference Guide, NIST Special Publication 1018, 2012.

15. Z. B. Chen, Wen, J.X., Xu B.P. and Dembele, S. The extension of eddy dissipation concept in the framework of Large Eddy Simulation and the subsequent modification. 23 ${ }^{\text {rd }}$ ICDERS, July 24-29, 2011, Irvine, USA.

16. S. Menon, Yeung P.K. and Kim W.W. Effect of subgrid models on the computed interscale energy transfer in isotropic turbulence. Computers and Fluids, 1996; 25:165.

17. F. L. Dryer and Glassman, I. High-temperature oxidation of $\mathrm{CO}$ and $\mathrm{CH}_{4}$. 14th Symposium (International) on Combustion. Pittsburgh : The Combustion Institute, 987-1003.

18. K. C. Adiga and Ramaker, D.E. Modeling pool-like gas flames of propane. Fire Safety J., 14, 241-250, 1989.

19. T. Beji, J. Zhang and Delichatsios M.A. Determination of soot formation rate from laminar smoke point measurements. Comb Sci and Tech, 180(5):927-940, 2008.

20. M.A. Delichatsios, A phenomenological model for smoke-point and soot formation in laminar flames. Comb Sci and Tech, 283-298, 1994.

21. E.J. Weckman and Strong A.B. Experimental investigation of the turbulent structure of medium-scale methanol pool fires. Comb and Flame, 105:245, 1996.

22. H.A. Becker, and Yamazaki, S., "Entrainment, momentum flux and temperature in vertical free turbulent diffusion flames. Comb and Flame, 33:123, 1978.

23. H.R. Baum, McGrattan K.B. and Rehm, R.G. Three dimensional simulation of fire plume dynamics. Journal of the Heat Transfer Society of Japan, 35(139) 45-52, 1997.

24. B.J. McCaffrey, Purely buoyant diffusion flames: some experimental results, Technical Report, NBSIR 79-1910, National Bureau of Standards, 1979. 